framework or organisation and cultural setting in which it is discussed. Just health care, whatever it is, is likely to be different in different countries.

Fust Health Care raises important issues, issues which merit more debate. Insofar as the book fosters such debate it is worth a read.

PROFESSOR GAVIN MOONEY Director, Health Economic Research Unit, University of Aberdeen, Department of Community Medicine, Foresterhill, Aberdeen

\section{The Place of the Humanities in Medicine}

Eric J Cassell, 56 pages, New York, $\$ 7.00$, Hastings Center, 1984

This essay reviews the place that the humanities have held in medicine in the past and examines what they have to offer to modern medical practice. It looks at the changes in attitude that are occurring in health care and considers ways that philosophy, history and literature can help our understanding and facilitate these changes.

The historic review is short and rather superficial. It concludes that the growth in emphasis on scientific training and method following the publication in 1910 of the Flexner Report on Medical Education led to the undervaluing of a liberal education as a foundation for a medical career. This attitude has persisted until the present.

However, there are some indications of a recent change in emphasis. The amount of teaching of various courses including ethics, literature, philosophy, human values, religion and medical history - in some American medical courses is discussed, and it is concluded that there is a growing awareness of the need for doctors to be versed in the scope and value of the humanities, and for an increase in curricular time devoted to these subjects.

What the humanities have to offer, and how best they can be communicated to medical students takes up the bulk of this short monograph, and this section concludes that medicine cannot progress unless the humanities are given a full role in medical education and practice. The obstacles to achieving a balanced education, and possible solutions, are put forward in the conclusion to this book.

The range of the humanities covered in this short work means that arguments cannot be developed in depth. Neither are different benefits emphasised for different liberal studies. While some useful arguments are put forward, it is unlikely that this book will persuade those now unconvinced, that medical schools should introduce liberal studies courses.

\section{St George's Hospital Medical School London SW17}

\section{Nursing Models: Analysis and Evaluation}

Janice A Thibodeau, 157 pages, Belmont, California, \$10.95,

Wadsworth Inc, 1983

It is difficult to discuss this book without naming at least some of its chapter headings. They are: The development of nursing science; The relationship of theory to model development; Historical development of models of nursing practice; Types of conceptual model; Criteria for analysis and evaluation of a nursing model; each of the following four chapters is used for the analysis of one of the models; the penultimate chapter deals with the implications of models of practice for nurse managers and the book concludes with a chapter on the future directions of nursing.

Appropriately and courageously, the author attempts to define important concepts such as theory, model, paradigm, which are so liable to misuse and lack of understanding. Understandably, but regrettably, she does not achieve the clarity hoped for and her own use of the terms in the text tends to be somewhat blurred.

A nursing paradigm is described as one which contains four essential components, namely people, health, environment and nursing; however, in her analysis of the four models using her four-pronged structural framework, the 'nursing' component could just as easily be applicable to other disciplines such as physiotherapy. Thus, the fundamental problem of this book lies in the definitions of the components of a nursing paradigm on which the analysis and evaluation is based; they are circular, tautological and self-defeating.

The book has many assets. The author has responded to the urgent need for a critical review of nursing models and their possible application. She has provided a helpful perspective especially in the historical chapters. She has attempted to apply her framework to some of the best known nursing models. The bibliographical references are excellent and should prove valuable starting points for further reading. This is a useful book for libraries as a source book for students of nursing theories and models. It is not easy reading for nurse practitioners and, in my view, it does little to bridge the gap between the doers and thinkers, the author's wish expressed in the first paragraph of chapter one. The most fundamental criticism so far as readers of this journal are concerned is the notable lack of analysis of the many ethical issues intrinsic to any 'nursing model'.

LISBETH HOCKEY Freelance consultant, writer and Guest Professor, University of Uppsala, Sweden

\section{Ethics and Mental Retardation}

Authors/Editors L Kopelman and J C Moskop, xvi +258 pages, Dordrecht, $\$ 29.50$, Dfl 11.90, D Reidel Publishing Company, 1984

I approached the reading of this book with some trepidation for two reasons. There is so little written on ethical issues in relation to mental handicap that I very much wanted this book to fill a large gap in my knowledge and in the literature. Secondly, I feared that the book would be so full of legal and ethical jargon that it would be turgid, uninteresting and hard to understand for the average British reader. I am glad that I was proved wrong on both counts. This book covers a wealth of subjects within the topic from the issue of rights and responsibilities, respect and the effect of labelling, the interface between religion and disability, the law and public policy. Despite this being a book from the USA (and all the contributors come from that country) much of what is written is relevant to what happens, or should be happening in Great Britain.

The book is a collection of writings taken from the papers presented at a symposium held in 1981 in North Carolina, supported by both the School of Medicine and the Department of Philosophy at East Carolina University. The title of the symposium was Natural Abilities and Perceived Worth: Rights, Values and Retarded Persons. While multi-author books and in particular books that follow a symposium run the risk of repeating information already known and reproducing articles that vary unacceptably in complexity, this book manages to avoid both. However, section 1, on Examining the Rights Tradition, written entirely by philosophers, is probably the most difficult for doctors.

Perhaps the section that interested me most was section 3 , which explored the link between theology and disabil- 
ity. The rhetorical question, Must God Create the Best?, is the title of the first paper and explores the Judaeo-Christian ethic that allows a less than perfect world to give room for God's grace to act.

Another paper in this section, entitled Parenting, Bonding and Valuing the Retarded, is of particular relevance for those who work with neonates. A sentence out of this chapter is a good example of the pithy language used in much of this book: 'Professionals cannot ... treat the child simply as a checked piece of luggage - containing so many grammes of bodyweight, lab values and deficits - and expect the child to come home and be embraced'.

I thoroughly recommend this book to those who want to delve deeper into the ethical issues relevant for mentally handicapped people and in particular to those who are willing to look at themselves, their own attitudes and expectations, and from where their motivation comes.

PROFESSOR JOAN BICKNELL Professor of the Psychiatry of Mental Handicap,

St George's Hospital Medical School London SW17

\section{Birth Reborn - What Birth Can and Should Be}

Michel Odent, 123 pages, London, £9.95, Souvenir Press, 1984

This book raises for me two ethical issues, one of which causes me no problems, whilst the other one does.

Michel Odent sets out in this book the attitudes that he has developed since 1962 , and describes the system that he is still developing in caring for childbearing women in the French provincial town of Pithiviers. In a nutshell, he believes that women should be in control of what happens to them when their babies are born and that medical intervention should be kept to a minimum. In respecting the dignity and feelings of individual women in labour he shows that the results can be as good, if not better, in terms of safety for both mother and child, to say nothing about emotional satisfaction, than birth by high technology. Almost everything that Odent says I can endorse without reservation. His beautifully illustrated account is convincing. It certainly will be to prospective parents, if not to sceptical midwives and obstetricians.

I have practically no difficulty in agreeing with everything that he says and does. I believe that he raises an ethical issue in challenging the established views of conventional obstetric practice, certainly in this country and in most others. I believe that Odent is morally right to propagate his views, because he can support them with observed and recorded facts.

But the second ethical issue leaves me with an unresolved conflict. The issue is whether or not it is right to create expectations for people bearing children that are dependent on one personality for their fulfillment, so much so that he becomes a 'cult' figure. The 'pilgrimage to Pithiviers' is a reality for many women either in fact or metaphorically. Such women believe, and a few even to the point of obsession, that only in Pithiviers can perfection in childbirth be achieved. I am sure that this is and was not intended by Michel Odent, nevertheless it has happened. I feel sure that Odent wishes women to be selfreliant both emotionally and physically during birth. I am also sure that he is right to wish this. But, I am sorry that in spite of what he may wish a cult has been created, because perfection in childbirth is not usually attainable, and because it cannot be right that only a minority of women are able to join the cult. However, I believe that it is necessary for professionals like Odent to polarise opinion, not only in order to change the attitudes of other professionals, but also to provide insight and strength for women themselves. My question remains, how do we change the attitudes of professionals towards childbearing women without creating dependence on the personality preparing the way for change?

PETER HUNTINGFORD Consultant Obstetrician, Maidstone Health District

\section{Current Opinions of the Judicial Council of the American Medical Association}

Prepared by the Judicial Council of the AMA, 47 pages, Chicago, $\$ 5$

paperback, 1984;

\section{The Handbook of Medical Ethics, 3rd edition}

British Medical Association, 111 pages, $£ 5$ to non-members, £2 to BMA members, London, 1984

These short texts cover a wide range of ethical problems relating to the professional responsibilities and obligations of physicians. The AMA text is the shorter of the two since it is not explicitly concerned with behaviour relating to broader moral issues. In contrast the BMA's Handbook offers a more thorough survey of the whole gamut of ethical issues.

At first sight there is little distinction between the two texts. Both begin with a short history of medical ethics, referring to the Code of Hammarabi, the Oath of Hippocrates, and Thomas Percival's Code of Medical Ethics of 1803. The differences which eventually emerge reflect the respective economic climates in which medicine is practised in the United Kingdom and the USA. There is, for example, much more attention to ethical problems arising out of fee-paying practices in the AMA Opinions which cover interest charges on fees, fee splitting, laboratory bills, and fees for surgical assistance. In this respect the AMA Opinions reflect a more contractual relationship between doctor and patient than the BMA guidelines. However, both deal in a similar way with certain crucial issues such as genetic engineering, termination of pregnancy, in vitro fertilisation confidentiality, use of computers, orgaw transplants, and the participation physicians in capital punishment whic is ruled to be contrary to the profession's ethics - the BMA extends this prohibition to the attendance at corporal punishment and the interrogation of prisoners.

Since it is the more comprehensive survey the BMA Handbook covers issues governing the relationship between doctors and individuals and between doctors and other groups in society. Like its American counterpart it surveys the relationship between professional discipline and the law. Of particular relevance are the ten pages dealing with ethical dilemmas which highlight areas where a broad consensus of opinion has been reached and where it has not. It might be objected that the discussion of ethical dilemmas is o restricted. In the light of the vast output of literature on terminal illness and death, where crucial discussions turn on the interpretation of expressions such as 'voluntary', 'active' and 'passive' euthanasia, the section dealing with this topic is brief to the point of being misleading. However, such brevity is compensated for by an up-to-date bibliography for further reference and several pages of ethical codes which are useful to have in one volume.

DAVID LAMB

Department of Philosophy, University of Manchester 